\title{
(Des)memória e catástrofe: considerações sobre a literatura pós-golpe de 1964
}

Ettore Finazzi-Agrò ${ }^{1}$

\begin{abstract}
O apagamento da memória coletiva das referências à tortura, bem como sua banalização, potencialmente reforçam as chances de naturalizá-la e ignorar a intensidade de seu impacto. O esquecimento é, nesse sentido, em si, uma catástrofe coletiva.
\end{abstract}

Jaime Ginzburg

Hoje, cinquenta anos depois, tudo parece ter voltado no álveo da História - todo o passado aparenta, então, se ter resumido numa listagem crua de fatos, num arquivo anônimo de nomes, silenciando, assim, centenas de histórias, apagando a memória viva das vítimas, limpando o sangue derramado, ocultando os corpos massacrados. Hoje, com efeito, parece que a violência e a repressão não estão mais na ordem do dia dos Estados ou ficam à margem na agenda dos governos, deixando espaço apenas para uma reconstrução "imparcial" do acontecido, para uma análise fria das causas e das consequências da ditadura. Hoje, de fato, aquilo que resta daquele ato brutal de supressão da democracia que foi realizado pelo golpe militar de 1964 é a contagem dos mortos e dos desaparecidos, sem levar em conta, senão de modo marginal, a dor procurada, o sofrimento daqueles que, inermes ou em armas, se opuseram a um Estado que fazia da exceção a sua regra.

Hoje, a violência ou é, por assim dizer, naturalizada, ou é pensada como um fenômeno dependendo do Fado, ou seja, do arbítrio de deuses transitórios e vingativos ou do capricho imperscrutável do Acaso, quase como se ela não fosse o produto da ação devastadora dos homens e dos governos, da hýbris que sempre se associa à vontade de poder e de domínio, à cobiça de quem esmaga e destrói para obter um lucro (simbólico ou material, pouco importa). Aquilo de que não se fala nem se deveria falar é, justamente, o nefas, ou seja, os gestos nefandos que, no Brasil, a Lei da Anistia - emanada em 1979 pelo regime militar ainda

${ }^{1}$ Doutor em letras e professor de literaturas portuguesa e brasileira na Faculdade de Letras e Filosofia da Sapienza - Universidade de Roma, Roma, Itália. E-mail: finazzi@uniroma1.it 
vigente - procurou apagar, deixando que a história fosse escrita pelos carrascos ou pelas vítimas, pela voz impudica dos torturadores e pela vergonha dos sobreviventes. Quanto à guerrilha do Araguaia, por exemplo, o famigerado Major Curió, com suas entrevistas recentes, e a falecida Elza Monnerat, com os seus depoimentos quase esquecidos, poderiam representar, como tantos outros entre opressores e oprimidos, os polos opostos, os nomes em dissonância dessa verdade outra, que cruza e embaralha a verdade da História a tornando, justamente, um emaranhado de histórias ou de narrativas sem nenhuma lógica consequencial. Nesse sentido, a meu ver, é só numa dimensão ficcional, é só no âmbito da literatura que podemos surpreender o nefas habitando nas dobras da História oficial, chegando assim a entrever aquele interdito que sempre se diz na defasagem e/ou na conjuntura entre duas versões contrapostas do mesmo acontecimento.

De resto, a violência como manifestação extrema e esmagadora do Outro nunca encontrou uma forma tão contundente de denunciar a opressão e o massacre dos inermes como aquela do discurso literário: pense-se apenas nos testemunhos da Shoah e em não só como ela não representou o abismo e o fim da poesia, segundo a conhecida hipótese de Adorno, mas, pelo contrário, como apenas a literatura conseguiu dizer aquela verdade que, no âmbito histórico, balançava (e que, de forma macabra, continua balançando) entre a afirmação e a negação, entra a denúncia documentada e a ultrajosa incapacidade de admitir o horror extremo dos "campos". Nesse sentido, são apenas os sobreviventes, para utilizar os termos de Primo Levi, que conseguem tomar a palavra em nome e por conta dos afogados, daqueles que não têm mais voz, das verdadeiras e já mudas testemunhas - daqueles, enfim, que pela condição de degradação em que permaneceram, experimentaram até o fim e o fundo a destruição daquilo que, no homem, marca a sua humanidade. Não por acaso Giorgio Agamben, na esteira justamente de Levi, identificou essa paradoxal "im-possibilidade" do testemunho na figura do assim chamado "muçulmano": aquele que vivenciou por completo o horror do holocausto, porque, usado frequentemente nos campos como Sonderkommando, habitou a ambígua condição de vítima e de cúmplice, sobrevivendo num estado que era, ao mesmo tempo, de não vida e de não morte - suspenso, enfim, naquele estado de "vida nua" que, uma vez atingido, consegue, por um lado, dar acesso ao papel de testemunha 
integral, proibindo, pelo outro, a esse homem reduzido a pura essência biológica de testemunhar.

Exatamente pelo fato de não viver, mas de sobreviver apenas presos no mecanismo da desumanização, engolidos pelo redemoinho do horror e demorando na soleira entra o humano e o animal -, só os "muçulmanos" seriam os detentores daquela verdade suprema ou ínfima que os supérstites, então, podem sim recontar ao mundo, sem todavia ter garantias tanto de ser considerados confiáveis por todos, quanto de conseguir relatar de forma exaustiva aquilo a que assistiram, porque o deles é justamente um conto, uma narrativa em que a realidade, por quanto ela possa ser relatada de modo objetivo, passa todavia através do filtro da subjetividade, se tornando, declaradamente ou não, ficcional. Não por acaso, os grandes livros sobre a Shoah, a partir de É isto um homem? e passando, por exemplo, pelas obras de Imre Kertész, são na sua maioria relatos que mantêm a estrutura romanesca.

Voltando ao caso brasileiro e aos anos da ditadura militar, embora a razão e a sucessão dos fatos - para além da dimensão e amplitude dos fenômenos de repressão - delineiem uma situação bem diferente daquela que se tinha dado na Europa pouco mais de vinte anos antes, encontramos todavia a mesma dificuldade da História em dar conta, de forma exaustiva, daquilo que realmente aconteceu e, sobretudo, em dar voz àqueles que não sobreviveram, aos que se afogaram no vórtice de violência provocado pelo Estado autoritário. Nesse sentido, o mérito das grandes sínteses historiográficas, assim como o empenho das organizações tentando resgatar a memória das vítimas, é com certeza enorme (estou pensando, em particular, nos quatro livros que compõem o ciclo sobre a ditadura escritos por Elio Gaspari, ou ao louvável trabalho levado adiante por livros e/ ou movimentos como Brasil: Nunca Mais), mas, apesar da sua fidelidade aos acontecimentos, apesar do seu escrúpulo documentário, essas obras não conseguem, a meu ver, mostrar de modo completo não aquilo que realmente aconteceu, mas a dor e o sangue, as lágrimas e as feridas que se abriram no corpo da Nação e na lembrança traumática dos sobreviventes. Aquilo que falta, mais uma vez, é a comoção pelos corpos torturados, pelas pessoas massacradas, pela dor dos sobreviventes - aquilo que falta, enfim, é o pathos que sempre acompanha a tragédia e a sua encenação: aquela compaixão "sororal" diante dos mortos, em suma, que, como no drama de Antígona, não consegue ter respostas, não abre para nenhuma kátharsis, 
apresentando-se, por contra, como o Imprescritível que impossibilita a absolvição e a desculpa - indulto e perdão que permanecem, aliás, os altos e louváveis objetivos das Comissões de Verdade instaladas no Brasil com em várias outras regiões do mundo.

Nesse sentido, a literatura cumpre um papel de suplência em relação à historiografia, conseguindo, às vezes, dizer o abjeto (para utilizar um termo evocado por Márcio Seligmann-Silva, 1999), conseguindo nos entregar aquela verdade nefanda e inter-dita que o relato ou a crônica dos acontecimentos não podem e, talvez, não devem dizer: que História seria, com efeito, aquela em que o autor manifesta o seu horror ou a sua comoção diante de fatos que ele deveria, em princípio, apenas relatar de forma lógica ou até "apática"? Entre as obras literárias tentando, pelo contrário, nos comunicar os extremos da violência, eu tomaria como exemplo um livro que, desde a sua publicação, dividiu a crítica entre aqueles que o consideraram um texto mostrando uma escassa "preocupação literária" (Süssekind, 2004, p. 76) e aqueles que sublinharam, por outro lado, a sua força representativa provindo "da qualidade estética da linguagem utilizada" (Candido apud Silva, 2008, p. 236-39): duas leituras, como se vê, contrapostas que não discutem, de modo explícito, o núcleo testemunhal ou político da obra, emitindo, todavia, julgamentos antitéticos sobre o seu valor literário. O livro em questão é Em câmara lenta, de Renato Tapajós, publicado em 1977 e logo censurado, e no qual, como numa cena em slow-motion (donde o título do livro), nos é apresentada, no capítulo final, primeiro a captura e a terrível tortura - cheia de detalhes cruentos - de uma jovem guerrilheira ("ela", no romance), que afinal morre, assim como morre, logo a seguir, numa cilada da polícia o seu companheiro de luta (nomeado apenas como "ele"). Se o episódio da tortura é contado na terceira pessoa, de forma aparentemente hiper-realista, a morte a tiros do seu companheiro começa na primeira pessoa para acabar, no momento em que "ele" é atingido por uma "rajada da metralhadora", com uma voz na terceira pessoa, constatando, como num amen fechando o livro, que "a deserção definitiva tinha sido realizada" (Tapajós, 1977, p. 176).

Sem querer entrar na polêmica sobre o valor estético da obra (que já envolveu críticos ilustres como aqueles que mencionei), acho que posso apenas sublinhar como o livro de Tapajós, testemunha e sobrevivente da repressão, escolhe a forma ficcional - embasada justamente nessa contínua mudança do ponto de vista - para dizer o horror dos anos da 
ditadura. Optando pela representação imagética ou até cinematográfica para denunciar a violência e o trauma, o escritor não pode, a meu ver, se filiar no âmbito da "literatura-verdade" (Süssekind, 2004, p. 73 e seguintes), mas naquele do tratamento poético e, por isso mesmo, subjetivo da realidade. Como escreveu Markus Lasch num ensaio recente - na esteira, aliás, das importantes observações sobre o mesmo texto de um crítico do porte de Jaime Ginzburg: ${ }^{2}$

O que opera no livro de Renato Tapajós são os procedimentos misteriosos da literatura, de poder tornar real o que é apenas ficcional e ficcional o que foi demasiado real. Foi aparentemente o poder da literatura que permitiu ao autor representar aquilo que se nega à e nega a representação. E é o poder da literatura que, por um breve momento, nos faz intuir comovidos o que, a rigor, não tem explicação (Lasch, 2010, p. 290).

Só o dispositivo literário e a sua potência (eu não usaria, aqui, a palavra "poder") conseguem, então, falar, tanto em prosa quanto em verso, do interdito, conseguem nos fazer intuir pela comoção e, eu acrescentaria, pela compaixão o inexplicável da violência, sem regra e sem medida, do homem sobre e contra o homem, se opondo assim ao dispositivo político-repressivo.

Eu diria, mais ainda, que em obras como Em câmara lenta (que desde a capa, aliás, se denomina como "romance" e não como "crônica" ou "depoimento") aquilo que ressalta não é tanto a crueza da escrita e a precisão, quase insuportável, da descrição da tortura e da morte quanto a raiz humana, intencional e propriamente política, do Mal. Uma encenação da violência, portanto, que é possível encontrar em muitos outros textos literários (estou pensando, entre inúmeros exemplos de descrições de torturas, num trecho de As meninas, de Lygia Fagundes Telles $^{3}$ ) e que acaba por tirar o gesto agressivo tanto da sua qualificação

\footnotetext{
${ }^{2}$ Vejam-se os seus fundamentais ensaios: "Imagens da tortura: ficção e autoritarismo em Renato Tapajós” e "Escritas da tortura”, agora republicados em Ginzburg (2012, p. 455-491).

${ }^{3}$ Transcrevo a seguir o trecho de As meninas apenas para mostrar como a cena da tortura incluída no livro de Tapajós não é absolutamente uma exceção na literatura pós-64: "Enrolaram então alguns fios em redor dos meus dedos, iniciando-se a tortura elétrica: deram-me choques inicialmente fracos que foram se tornando cada vez mais fortes. Depois, obrigaram-me a tirar a roupa, fiquei nu e desprotegido. Primeiro me bateram com as mãos e em seguida com cassetetes, principalmente nas mãos. Molharam-me todo, para que os choques elétricos tivessem mais efeito. Pensei que fosse então morrer. Mas resistia e resisti também às surras que me abriram um talho fundo em meu cotovelo. Na ferida o sargento Simões e o cabo Passos enfiaram um fio. Obrigaram-
} 
técnica - o mecanismo e a estratégia repressivas - quanto da sua explicação natural - o mal como fenômeno fatal e incontrolável, dependendo apenas de uma vontade imperscrutável e meta-histórica. ${ }^{4}$ Considerando, de fato, o sofrimento infligido enquanto produto de uma causa imponderável e anônima, teremos como resultado a justificação e a irresponsabilidade daqueles que provocam o sofrimento e a impossibilidade para as vítimas de denunciar o acontecido. O verdadeiro culpado seria, nessa perspectiva, sempre uma instância outra e superior que se subtrai ao julgamento, justamente pelo fato de agir "em força de lei" e de obedecer a um poder sem vulto e sem nome e onde não se pode nomear o carrasco, quando não se consegue dar uma identidade ao responsável não há nem mesmo a possibilidade de atribuir e punir a culpa.

Para retomar a metáfora trágica, ao contrário do respeito cego e impiedoso da Lei por parte de Creonte, a pietas mostrada por Renato Tapajós diante dos corpos trucidados o leva a reclamar, em voz alta, o respeito que se deve a eles. E, se anônimo e cruento é o Poder, anônimos e inspirados pela mesma cruel determinação são os personagens que a ele se contrapõem: jovens sem nome combatendo movidos por um ideal ambíguo e inexequível, para a realização de uma utopia destinada à derrota e, justamente, à "deserção definitiva". Nenhum nome, de fato, é possível numa situação em que carrascos e vítimas são os emblemas de uma humanidade denegada: como no romance mais conhecido de Primo Levi, assim naquele de Tapajós o que está em questão é a própria humanidade de um sujeito reduzido a um "isto", a uma pura indicação, a um puro dêictico, como dêicticos - assumindo, então, um significado transitório e sem referência senão ao próprio discurso que os contém -

me a então a aplicar os choques em mim mesmo e em meus amigos. Para que eu não gritasse enfiaram um sapato dentro da minha boca. Outras vezes, panos fedidos. Após algumas horas, a cerimônia atingiu seu ápice. Penduraram-me no pau-de-arara: amarraram minhas mãos diante dos joelhos, atrás dos quais enfiaram uma vara, cujas pontas eram colocadas em mesas. Fiquei pairando no ar. Enfiaram-me então um fio no reto e fixaram outros fios na boca, nas orelhas e mãos. Nos dias seguintes o processo se repetiu com maior duração e violência. Os tapas que me davam eram tão fortes que julguei que tivessem me rompido os tímpanos: mal ouvia. Meus punhos estavam ralados devido às algemas, minhas mãos e partes genitais completamente enegrecidas devido às queimaduras elétricas” (Telles, 1985[1973], p. 135).

${ }^{4}$ Quanto ao valor tecnológico atribuído à tortura e/ou à sua assimilação aos fenômenos "naturais" no Brasil da ditadura, veja-se ainda Ginzburg (2012, p. 484-491). 
são os pronomes pessoais "ele" e "ela", emblemas de uma opção política apagando qualquer identidade pessoal.

Por outro lado, não se pode esquecer que o esmagamento dos dois protagonistas chega, acompanhado por um leitor compadecido, até a morte de ambos, como se o autor quisesse comprovar ou antecipar a hipótese sobre a possível impossibilidade e sobre a impossível possibilidade do testemunho, assim formulada por Agamben:

Exatamente pelo fato de o testemunho ser a relação entre uma possibilidade de dizer e o seu ter lugar, ele pode se dar apenas através da relação com uma impossibilidade dizer - ou seja, apenas como contingência, como um poder não ser. [...] O testemunho é uma potência que se dá realidade através de uma impotência de dizer e uma impossibilidade que se dá existência através de uma impossibilidade de falar. Esse dois movimentos não podem nem se identificar num sujeito ou numa consciência, nem se apartar em duas substâncias incomunicáveis. Essa inseparável intimidade é o testemunho (Agamben, 1998, p. 135-36).

Nessa perspectiva, um escritor/testemunha/partícipe como Tapajós não nos dá, apenas, "em câmara lenta" a descrição pormenorizada da tortura e da morte da mulher, mas nos apresenta, em câmara subjetiva, também a cilada e a morte de quem está nos falando. Em ambos os casos temos a ver com situações "impossíveis" ou "inverossímeis", dado que se conta em detalhe uma tortura a que o autor não assistiu e um assassinato que é contado pelo próprio sujeito assassinado. Isso mostra, justamente, o caráter contingente - e, afinal, necessariamente e integralmente ficcional - do testemunho, balançando, como na hipótese de Agamben, entre uma possibilidade de falar (a do escritor, sobrevivente e supérstite, que de fato fecha o romance com uma frase em off pronunciada/escrita por ele) e a impossibilidade de o fazer de forma integral (os que morrem não poderiam, evidentemente, testemunhar ou descrever a sua própria morte).

No âmbito da literatura produzida durante ou sobre a época da ditadura militar, o livro de Renato Tapajós, constitui, nesse sentido, uma espécie de unicum, visto que, pelo menos que eu saiba, não existe alguém que se tenha adiantado até os limites da expressão e do exprimível, chegando a "representar aquilo que se nega à e nega a representação", para retomar as palavras de Markus Lasch. Prescindindo, mais uma vez, do valor estético do romance, creio que o 
texto de Tapajós mereça ser lembrado exatamente por causa dessa vontade de dizer o indizível ou o nefando, de tornar possível, "diante do extremo", a impossibilidade do testemunho. Existem, com certeza, muitas obras de grande impacto, descrevendo, de forma direta e autobiográfica ou de modo indireto e paradoxal, os sofrimentos infligidos pela ditadura militar (estou pensando, no primeiro caso, em livros de memórias como $O$ que é isso companheiro?, de Fernando Gabeira, ou como Os carbonários, de Alfredo Sirkis; no segundo, em obras irônicas como A festa, de Ivan Ângelo, ou como Confissões de Ralfo, de Sérgio Sant'anna - que traz, não por acaso, o subtítulo "uma autobiografia imaginária"). Acho todavia que o romance de Tapajós guarda a especificidade, por um lado, de ir além da autobiografia e da crônica e, pelo outro, de ficar muito aquém do tratamento irônico de uma realidade opressiva e oprimente, para nos mostrar a dedo o destino trágico de "ele" e "ela", para indicar os corpos machucados e abandonados, para dar voz aos mortos que permanecem as testemunhas integrais e mudas de uma História confiada apenas aos supérstites.

São muitas, de resto, as obras que nos falam da dor dos sobreviventes - obras muito diferentes cujo único objetivo, porém, é o de denunciar, em diversos registros, de modo crítico e também autocrítico, as mazelas da ditadura e, às vezes, os erros daqueles que a ela se opuseram, de forma armada ou não. Em geral, porém, trata-se de obras escritas e/ou publicadas nos anos da abertura do regime militar ou, como no caso do envolvente $K$, de Bernardo Kucinski, depois da derrota da ditatura: esse estar fora do período mais duro da repressão e da censura (depois do AI-5) não tira nada ao valor das obras, mas constitui, a meu ver, já uma tentativa de elaboração do trauma, enquanto o romance de Tapajós nos faz continuamente reviver os atos sangrentos da repressão e os gestos desesperados da luta.

Um discurso à parte mereceriam, na minha opinião, romances como Bar Don Juan e Reflexos do baile, de Antonio Callado, não, talvez, apenas pelo fato de serem obras de maior qualidade em relação às outras, mas pelo fato de terem sido escritas e publicadas no calor da hora. O primeiro romance, com efeito, foi editado em 1970, num momento, então, de forte repressão e de censura de qualquer expressão antirregime. $\mathrm{O}$ fato surpreendente de não ter sido proibido mostra apenas o descuido e a ignorância dos censores, visto que o romance se abre, justamente, onde se conclui Em câmara lenta, ou seja, com uma cena 
onde um homem e uma mulher relembram a tortura dele e a violência carnal dela, às quais o casal tinha sido submetido duas semanas antes, durante um interrogatório por parte da polícia militar. Bar Don Juan, como aliás muitos dos livros escritos por Callado, é um romance coral, se apresentando como crônica de uma geração - aquela que, utilizando o título de um famoso romance de Pepetela, poderíamos denominar "a geração da utopia", ou seja, dos jovens que, fascinados pelo mito da revolução cubana e pela figura do Che Guevara, imaginaram poder derrubar o regime militar brasileiro, exportando a insurreição marxista em todas as regiões da América Latina.

Callado descreve a parábola dolorosa desses homens e mulheres, na sua maioria intelectuais, que lutaram até a derrota contra um Poder que, na realidade, demostrou ser ferozmente determinado e muito bem organizado - do ponto de vista, mais uma vez, tecnológico -, ao contrário das expectativas sem fundamento daqueles que sonharam com uma vitória da luta armada. Nessa descrição indignada, não falta ainda certa dose de ironia, típica do escritor, que já circulava no seu romance mais conhecido, Quarup, de 1967, e que vai se manifestar, de modo ainda mais claro, no romance seguinte, Reflexos do baile, de 1976, em que o período da ditadura é encarado de forma declaradamente paródica e paradoxal, na imagem grotesca do seu aparato repressivo e na fragmentação ilimitada das vozes dos carnífices e das vítimas, que se entrecruzam ou se distanciam sem parar.

Para recompor o quadro da ditadura e dos seus efeitos, essa mudança contínua tanto do registro expressivo quanto do ponto de vista parece fundamental rumo a uma representação participada e, ao mesmo tempo, estranhada de uma época de atrocidades e de projetos de resgate sempre falhados. Nesse sentido, os textos literários, em relação aos depoimentos pessoais ou aos documentos colecionados pelos historiadores, guardam uma vantagem evidente: aquela margem de liberdade que permite aos escritores mergulhar no horror ou se distanciar dele para denunciar o grotesco que muitas vezes se associa ao nefando. ${ }^{5}$ De resto, o testemunho é sim marcado pela "fiabilidade" ou

${ }^{5}$ Quanto à Shoah, podemos lembrar, por exemplo, as considerações avançadas por Márcio Seligmann-Silva: “Apenas a passagem pela imaginação poderia dar conta daquilo que escapa ao conceito. Semprún e outros sobreviventes da Shoah sabem que aquilo que transcende a verossimilhança exige uma reformulação artística para a sua transmissão, Mas a imaginação não deve ser confundida com a "imagem": o que conta é a capacidade de criar imagens, comparações e 
pela "con-fiança", mas em qualquer depoimento ecoa ainda e sempre a origem latina do auctor fio, ou seja, a fórmula antiga pela qual alguém se declarava "autor" e garantia de uma verdade que dependia da sua interpretação dos fatos. Nessa perspectiva, como escreveu ainda Agamben, "o testemunho [...] implica sempre uma dualidade essencial, em que uma insuficiência ou uma incapacidade são integradas e validadas" (Agamben, 1998, p. 140).

O papel da literatura é, justamente, centrado nesse irremediável dualismo, ou melhor, nesse habitar instâncias opostas, conseguindo exprimir o inexprimível através de uma contínua alteração ou alternância de registros (do trágico ao cômico), por meio de uma mudança vertiginosa dos pontos de vista (do mais aleatoriamente subjetivo ao mais rigorosamente objetivo), sem que isso tire nada à função testemunhal dos textos. Mais uma vez, o valor estético das obras produzidas no e sobre o período da ditadura militar não depende tanto do grau de fiabilidade delas quanto da capacidade do autor de fazer passar, através da sua escrita e das imagens por ele produzidas, uma verdade material - "física", eu diria - da qual nenhuma História poderia dar conta senão traindo ao seu estatuto epistemológico. De fato, aquilo que as muitas histórias sobre a repressão e a tortura conseguem nos legar é, justamente, a dor e o sangue, a vergonha e a insensatez de um mundo social e político que, cinquenta anos atrás, se enviesou, perdeu o seu eixo, vivendo num perene estado de exceção e tornando o Mal e a Violência as únicas regras de uma conduta sem regras, visando apenas ao aniquilamento das diferenças e impondo o domínio biológico sobre a vida dos "outros" - dos inconformados, de sujeitos que perderam o seu estatuto humano se tornando apenas "eles".

\section{Referências}

AGAMBEN, Giorgio (1998). Quel che resta di Auschwitz: l'archivio e il testimone. Torino: Bollati Boringhieri.

CALLADO, Antonio (1982[1970]). Bar Don Juan. 7. ed. Rio de Janeiro: Civilização Brasileira.

sobretudo de evocar o que não pode ser diretamente apresentado e muito menos representado" (Seligmann-Silva, 2003, p. 384) 
(1977). Reflexos do baile. 4. ed. Rio de Janeiro: Paz e Terra.

GINZBURG, Jaime (2012). Crítica em tempos de violência. São Paulo: EDUSP, Fapesp.

LASCH, Markus (2010). Em câmara lenta: representações do trauma no romance de Renato Tapajós. Remate de males, Campinas, v. 30, n. 2, p. 277-291.

SELIGMANN-SILVA, Márcio (1999). Do delicioso horror sublime ao abjeto e à escritura do corpo. In: ANDRADE, C. et al. (orgs.). Leitura do ciclo. Florianópolis: Abralic.

(2003). O testemunho entre a ficção e o "real". In: SELIGMANN-SILVA, Márcio (org.). História. Memória, literatura: o testemunho na Era das Catástrofes. Campinas: Editora da Unicamp.

SILVA, Mário Augusto Medeiros da (2008). Os escritores da guerrilha urbana: literatura de testemunho, ambivalência e transição política (1977-1984). São Paulo: Annablume, Fapesp.

SÜSSEKIND, Flora (2004). Literatura e vida literária: polêmicas, diários \& retratos. 2. ed. Belo Horizonte: Editora UFMG.

TAPAJÓS, Renato (1977). Em câmara lenta. 2. ed. São Paulo: Alfa-Omega.

TELLES, Lygia Fagundes (1985[1973]). As meninas. 26. ed. Rio de Janeiro: Nova Fronteira.

Recebido em dezembro de 2013.

Aprovado em janeiro de 2014.

\section{resumolabstract}

\section{(Des)memória e catástrofe: considerações sobre a literatura pós-golpe de 1964}

Ettore Finazzi-Agrò

O texto pretende repensar, na esteira de uma tradição crítica consolidada, o papel da literatura na representação e na denúncia dos atos de repressão realizados pelo regime militar brasileiro a partir de 1964 e, com maior contundência e força, a partir de 1968, depois da promulgação do AI-5. Nesse âmbito, a função das histórias - contadas por diversos autores e por alguns dos sobreviventes da repressão - parece ser, sobretudo, aquela de desenvolver um papel de suplência da História, no sentido de mostrar, de modo eficaz e através da ficção, o nefando que caracterizou em particular a tortura e o assassinato dos opositores. O estatuto da literatura - a sua capacidade de dizer aquilo que é 
interdito à historiografia, a possibilidade de recriar o real através da imaginação - permitiu, de fato, a muitos escritores testemunhar o horror e a violência que marcaram o regime instaurado no Brasil cinquenta anos atrás, chegando a nos dar a representação "física" da dor e do sangue derramado por um Poder agindo em estado de exceção.

Palavras-chave: ditadura militar, literatura brasileira, testemunho.

\section{(Des)memory and disaster: reflexions on the literature after the coup d'état of 1964}

\section{Ettore Finazzi-Agrò}

The text aims to rethink, in the wake of an established critical tradition, the role of literature in the representation and complaint of acts of repression carried out by the Brazilian military regime since 1964, and with greater forcefulness and strength, since 1968, after enactment of Institutional Act n. 5. In this context, the stories - told by many authors and some of the survivors of repression - seem to play an important role in supplying the deficiencies of the History, in order to show, effectively even if through fiction, the nefas that characterized in particular torture and murder of opponents. The status of literature - his ability to say what is forbidden to historiography, the possibility of recreating the real through imagination - drove, in fact, many writers to witness the horror and violence that marked the regime established in Brazil fifty years ago, even giving us the "physical" representation of pain and blood generated by a power acting in a "state of exception".

Keywords: military dictatorship, Brazilian literature, testimony. 